\title{
Development and piloting of a community health worker-based intervention for the prevention of diabetes among New Zealand Maori in Te Wai o Rona: Diabetes Prevention Strategy
}

\author{
D Simmons ${ }^{1, *}$, R Rush $^{2}$ and N Crook ${ }^{3}$, on behalf of the Te Wai o Rona: Diabetes \\ Prevention Strategy Team \\ ${ }^{1}$ Institute of Metabolic Science, Cambridge University Hospitals NHS Foundation Trust, Cambridge CB2 2QQ, \\ UK: ${ }^{2}$ Centre for Physical Activity and Nutrition Research, AUT University, Auckland, New Zealand: ${ }^{3}$ Lakes \\ District Health Board, Rotorua, New Zealand
}

Submitted 6 August 2007: Accepted 16 April 2008: First published online 12 June 2008

\begin{abstract}
Objective: The progression from impaired glucose tolerance (IGT)/impaired fasting glucose (IFG) to type 2 diabetes can be prevented or delayed through intensive lifestyle changes. How to translate this to implementation across whole communities remains unclear. We now describe the results to a pilot of a personal trainer (Maori Community Health Worker, MCHW) approach among Maori in New Zealand.

Design, setting and subjects: A randomised cluster-controlled trial of intensive lifestyle change was commenced among 5240 non-pregnant Maori family members without diabetes from 106 rural and 106 urban geographical clusters. Baseline assessments included lifestyle questionnaires, anthropometric measurements and venesection. A pilot study (Vanguard Study) cohort of 160 participants were weighed before and during MCHW intervention, and compared with fiftytwo participants weighed immediately before intervention and with 1143 participants from the same geographical area. Interactions between participants and the $\mathrm{MCHW}$ were reported using personal digital assistants with a programmed detailed structured approach to each interview.

Results: During the Vanguard Study, participants and MCHW found the messages, toolkit and delivery approach acceptable. Those with IGT/IFG diagnosed ( $n$ 27) experienced significant weight loss after screening and during the Vanguard Study $(5 \cdot 2$ (sD $6 \cdot 6) \mathrm{kg}$, paired $t$ test $P<0 \cdot 01)$. Significant weight loss occurred during the Vanguard Study among all participants $(-1 \cdot 3$ (sD $3 \cdot 6) \mathrm{kg}, P<0 \cdot 001$ ).

Conclusions: Comparable initial weight loss was shown among those with IGT/ IFG and those from existing trials. Community-wide prevention programmes are feasible among Maori and are likely to result in significant reductions in the incidence of diabetes.
\end{abstract}

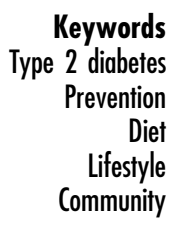

Intensive lifestyle intervention through ongoing personal support prevents/significantly delays progression from impaired glucose tolerance (IGT) to type 2 diabetes ${ }^{(1-4)}$, reduces cardiovascular risk and improves other components of the metabolic syndrome ${ }^{(1,5)}$. Such lifestyle change can be sustained and continue to reduce diabetes incidence after individual counselling has stopped ${ }^{(6)}$. However, a strategy to identify and treat only those with IGT will not prevent growth in numbers with pre-diabetes or obesity, and implementation can be costly ${ }^{(7)}$.

Lesser degrees of weight control (reductions in weight gain), potentially of use for sustaining diabetes prevention, are possible through community-based programmes ${ }^{(8-11)}$, although these are often fraught with difficulties ${ }^{(8,9,12,13)}$. Interruption of the supply of energy-dense foods in isolated communities and promotion of traditional lifestyles can also have an effect on diabetes risk ${ }^{(10,14)}$, although these are unlikely to be practical in most populations and particularly in urban areas.

We hypothesised that the degree of 'personal trainer' support required for those with IGT/impaired fasting glucose (IFG) ${ }^{(1,4)}$ to adopt and maintain intensive lifestyle change can be reduced through facilitating comparable lifestyle change among others in the family and community. Such an approach could also: (i) reduce the proportion progressing from normal to abnormal glucose tolerance overall (not just those with IGT/IFG); (ii) remove the need for screening (beyond that required clinically); (iii) benefit those without significant risk factors currently (e.g. children); (iv) reduce the prevalence of other metabolic syndrome 
components; and (v) potentially be more affordable than the current 'high-risk' approaches.

We now describe the study design, intervention framework and feasibility/pilot study of the 'personal trainer' approach for Te Wai o Rona: Diabetes Prevention Strategy, a randomised cluster-controlled participatory research trial of intensive lifestyle change, established to test our hypothesis among New Zealand Maori, a population at high risk of type 2 diabetes ${ }^{(15)}$. The intervention was built upon our previous work in Polynesian communities $^{(11,12)}$. With such prior experience and as the intervention was expected to evolve through the trial (being action research) and become increasingly tailored to the participating communities, we undertook the pilot as a 'Vanguard Study', i.e. at the beginning of the trial. Its purpose was to test the tools used and assess the impact of the intervention within the first study participants.

\section{Subjects and methods}

\section{Goals and power}

Te Wai o Rona: Diabetes Prevention Strategy was registered in 2005 as a 4-year randomised controlled trial with the Australasian Controlled Trials Registry (ACTRN012605000622606) with the primary research goal of demonstrating a $35 \%$ reduction in incident diabetes among Maori and other adult household members with varying levels of glucose tolerance. This target was agreed upon as it was felt that the intervention was likely to be less effective than either the Diabetes Prevention Program or the Finnish Diabetes Prevention Study (FDPS) ${ }^{(1,4)}$, but more effective than expected with minimising weight gain over the study period ${ }^{(16)}$. Consistent with the hypothesis, cost-effectiveness was not expected to be calculable until the community support/action activities were fully developed (using action research principles $^{(17)}$ ) after 3-4 years, with a cost goal of NZ\$200 per head per annum.

Diabetes, IFG and IGT were diagnosed using 1998 WHO criteria ${ }^{(18)}$. Participants with a single test indicative of diabetes were excluded from the trial irrespective of the results of any follow-up tests. The trial intervention was undertaken through local District Health Boards (DHB) to allow a seamless roll-out of the intervention if shown to be affordable and effective.

To determine sample size, progression rates to diabetes were derived from those found in Mauritius for men and women with IGT $(12 \cdot 0 \%$ and $8 \cdot 1 \%$ per annum, respectively) and IFG $(6 \cdot 1 \% \text { and } 7 \cdot 5 \% \text { per annum })^{(19)}$. The initial prevalence rates of IGT/IFG were based upon a prior survey among Maori ${ }^{(20)}$. Dropout was assumed to be $10 \%$ per annum, intra-cluster correlation to be $0.02, \alpha$ as 0.05 with a power of $80 \%$ : 4976 participants were required to show a $35 \%$ reduction in incident diabetes from IGT/IFG over 4 years. The study had the power to detect a difference of $0 \cdot 2 \%$ in glycosylated $\mathrm{Hb}$ (HbA1c), but insufficient power to compare progression rates from normal to IGT/IFG.

\section{The population, inclusion and exclusion criteria}

Recruitment population was defined by the boundaries of the Waikato DHB and the tribal area of Ngati TuWharetoa in the neighbouring Lakes DHB. This area occupies $28190 \mathrm{~km}^{2}$, with an estimated total population of 368811 including 81991 Maori in $2004^{(21)}$. District Health Boards are responsible for funding health services in geographically defined areas (twenty-one across New Zealand) and include Maori with both Board and Executive responsibilities.

As a family-based intervention developed around traditional and contemporary Maori culture, all members of any family including at least one Maori within the same household were eligible for entry into the study. The age cut-off for entry was taken as $\geq 28$ years on 30 September 2005. All residents with past gestational diabetes mellitus, and those aged 23 years and over with both parents with known diabetes, were also considered eligible. Those unfit to sign a consent form, with terminal disease or not permanently residing in the study area at the time of the baseline data collection were excluded. Ethical approval was provided by both the Waikato and Bay of Plenty Ethics Committees (which include Maori representatives). All participants gave signed informed consent.

\section{Randomisation to MCHW-supported lifestyle intervention}

As a combined community, family and personal intervention within relatively close-knit communities, it was important to choose the best method for maximising collective community and family change in those individuals randomised to intensive lifestyle change, while minimising contamination of the controls. Options included through individuals, extended families (whanau), affiliation with local meeting houses (marae), households and small census areas. The latter was chosen, particularly to take account of the frequent close proximity of Maori households and the large number of Maori from outside the area, away from their tribal area and/or in the urban areas.

A stratified cluster randomisation was undertaken to maximise the chance of comparable numbers and characteristics within each limb. Cluster randomisation within each stratum was done using an electronic randomiser within SPSS (SPSS Inc., Chicago, IL, USA). Randomisation occurred until $50 \%$ of clusters in a stratum were randomised to intensive or control.

Five rural strata, with 106 clusters, were created from the 2001 census data by the number of adult Maori. Some areas with fewer than thirty-five residents were felt to be unlikely to have enough responders and came under a nearby cluster. Urban strata were randomised within the 
two largest towns creating 106 clusters of 75-150 adult Maori defined by NZ statistics census areas. Randomisation created fifty-two rural and fifty-four urban intensive clusters and fifty-four rural and fifty-two urban 'additional' clusters (so called as participants in these latter areas received screening, their results and other information).

\section{Recruitment}

Recruitment occurred between May 2004 and March 2006 and involved written invitations from local general practitioners (GP), media releases (television, radio, posters, newspapers) announcing times/venues of screening, personal contact through different health organisations and their staff, and announcements at a number of Maori community activities. Those who attended were asked to inform other family members and friends.

\section{Measurements}

Staff were trained and standardised in questionnaire and measurement completion. Sessions were held between 07.00 and 14.00 hours in a variety of community venues across the study area. Transport was provided for participants where possible. Participants were asked to attend after a $10 \mathrm{~h}$ overnight fast, although attending non-fasting was acceptable (although an oral glucose tolerance test (OGTT) was not then performed). After registration/ consent and ascertainment of fasting status, fasting participants had a finger-prick glucose test (venous plasma equivalent) using a glucose meter (Advantage; Roche, Switzerland). Those who were non-fasting had a single venesection for glucose and HbA1c (Bio-Rad Diamat Variant (upper limit of reference range 6.4\%); Bio-Rad Laboratories, USA). Fasting participants with a fingerprick glucose $\geq 4.4 \mathrm{mmol} / 1$ were invited to undertake a $75 \mathrm{~g} 2 \mathrm{~h}$ OGTT. Questionnaires were completed with assistance and included demographic data, fasting status, stage of change for lifestyle ${ }^{(22)}$, the revised Physical Activity Readiness Questionnaire (rPAR-Q) ${ }^{(23)}$ and a number of health, food and lifestyle-related questions.

Participants were measured in six private booths with a set of equipment at each booth. Measurements included height without shoes using a stadiometer (to the nearest $0.5 \mathrm{~cm}$ ) and weight in light clothing and without shoes to the nearest $0 \cdot 1 \mathrm{~kg}$ (Wedderburn TITH316 Personal scales), using Wedderburn TI-BWB800 Personal scales (up to $200 \mathrm{~kg}$ ) for oversize participants. Waist was measured on standing participants, at the lateral midpoint between the lower rib and the iliac crest. All measurements were taken in duplicate, and repeated if beyond a specified tolerance level.

Based upon previous research including Maori ${ }^{(24)}$, if no OGTT had been completed and the fasting glucose was $\geq 5.3 \mathrm{mmol} / 1$ or a random glucose $\geq 5.3 \mathrm{mmol} / \mathrm{l}$ or the $\mathrm{HbA} 1 \mathrm{c} \geq 5 \cdot 3 \%$, participants were asked to attend the local community laboratory for an OGTT. Samples for HbA1c were sent to the same laboratory for analysis.

\section{The intervention}

All participants received a copy of their results with relevant comments regarding abnormal results and were advised to visit their GP where necessary. The 'intensive' intervention included personal support delivered by a MCHW (built upon previous experience ${ }^{(25)}$ ) employed across eleven Maori Health Providers. In the intensive areas, social mobilisation to maximise support for lifestyle change was planned based upon previous experience $^{(8,11-13)}$. The MCHW was trained to deliver the intervention using principles based upon social cognitive theory ${ }^{(26)}$ and tailored to the stage of change for any individual lifestyle behaviour ${ }^{(13,22,27)}$. Participants with significant risk from physical activity on $\mathrm{rPAR}-\mathrm{Q}^{(23)}$ in the intensive group were provided with a subsidised visit to see their GP for consideration for a 'Green Prescription' ${ }^{\text {(28) }}$, to advise on the intensity of physical activity considered safe, and referral for a single counselling session with a Maori exercise coach.

The FDPS showed that those adopting at least four of their five 'lifestyle goals' did not progress to diabetes over the initial study period ${ }^{(1)}$. These 'lifestyle goals' were mapped onto lifestyle changes (themselves expressed as 'messages'), expected to be required and potentially achievable through small changes. Lifestyle changes were based upon existing Maori dietary and physical activity behaviours ${ }^{(29,30)}$ and through a series of working groups including local Maori elders, Maori and non-Maori health workers and researchers. During this process, a set of goals emerged emphasising a reduction in total energy consumption including from simple carbohydrate consumption, and dropping the ' $<30 \%$ of energy intake from fat' goal of the FDPS. Table 1 shows the messages, goals and their linkages.

MCHW training was provided in modular form covering basic anatomy and physiology, communication skills, motivational interviewing ${ }^{(31)}$, broader health issues and the content and background to the twelve messages of the lifestyle intervention. A desk file (including safety and engagement principles and intervention approach) and toolkit supporting the twelve messages were created from existing materials or developed de novo and distributed in a case to each MCHW. Part of this toolkit was a personal digital assistant (PDA) (QTek; Vodafone, HTC, Taiwan) with a program including a register of participants allocated to the MCHW, providing information from the screening and a detailed, structured approach to the interview. Each MCHW was allocated a set of scales (Bathroom scales 62813, 0-150 kg; Soehnle, Germany) and weight was measured when agreed; however, the focus was on achieving the lifestyle changes, not weight change. Information was recorded into the PDA interface forms with structured fields throughout each interaction. The PDA was synchronised at the end of each encounter (by phone or face to face) and information merged with the rest of the participant data, based on the unique 
Table 1 Te Wai o Rona: Diabetes Prevention Strategy - twelve messages, eleven goals and their linkages

\begin{tabular}{|c|c|c|}
\hline $\begin{array}{l}\text { Message } \\
\text { Balance, Moderation and Variety - choice. } \\
\text { Small changes will add up to big difference }\end{array}$ & $\begin{array}{l}\text { This message links to the } \\
\text { following goals }\end{array}$ & $\begin{array}{c}\text { Goals - prevent or delay onset } \\
\text { of diabetes by }\end{array}$ \\
\hline Look for ways to be active every day & $1,2,3-6$ & 1. Loss of body weight $5 \%$ \\
\hline Increase daily exercise and include intense exercise & $1,2,3-6$ & 2. Reduction in waist measurement \\
\hline Move more add more steps & $1,2,3-6$ & 3. Increase energy used in activity \\
\hline Choose to be strong & $1,2,4,6$ & 4. Improve muscle strength \\
\hline Reduce sedentary leisure time & $1,2,3-6$ & 5. Improve aerobic capacity - endurance \\
\hline Drink water - drink more water & $1,2,7,10,11$ & 6. Reduce time spent being inactive \\
\hline Minimum $5+$ fruit and veg/d $=$ increase fruit and vegetable & $1,2,8,11$ & 7. Decrease simple sugar intake \\
\hline Choose more variety of protein containing foods & $1,2,9,10,11$ & 8. Increase fibre \\
\hline Eat less fat $=$ decrease fat intake & $1,2,10$ & 9. Reduce saturated fat \\
\hline Watch the portion size & $1,2,10$ & 10. Reduce total energy in diet - eat less \\
\hline Eat more fibre & $1,2,8,11$ & 11. Reduction of appetite \\
\hline Eat less sugar $=$ decrease simple sugars & $1,2,5,11$ & \\
\hline
\end{tabular}

No emphasis on alcohol was made.

participant ID. The first encounter (at the very least) was for familiarisation (known as whakawhanaungatanga) at which the PDA was usually not used, although purpose and perhaps some materials were provided. This was at the discretion of the MCHW. MCHW were advised to prioritise those with IGT/IFG. Caseloads were expected to vary according to rurality and recruitment, but on average were expected to be between 160 and 250 . Group sessions (but not class-based education as in the Diabetes Prevention Programme (DPP) ${ }^{(2)}$ ) as in our previous programmes ${ }^{(11,12)}$ were expected to develop through the local communities, through the participatory research approach ${ }^{(17)}$ and were not a significant part of the pilot study.

\section{The Vanguard pilot/feasibility study}

Overall, 5240 non-pregnant Maori family members, without known diabetes, were recruited into Te Wai Rona: Diabetes Prevention Strategy across the Waikato and Lakes DHB catchment areas. The Vanguard Study, nested within the overall study, tested the MCHW coaching and associated tools in the intensive clusters in four geographical areas (three rural and one urban) chosen by the readiness of their allocated $\mathrm{MCHW}$. All participants who had entered the trial and received their results at the time of the pilot were invited to participate. Figure 1 shows the source of the sample. The Vanguard Study was completed on 3 March 2006. Those in the Vanguard Study were not different from the complete cohort by age, sex or socioeconomic status. In February 2006, measurements were obtained before intervention among participants in the initial area who had been recruited too late to enter the pilot ('controls'). The baseline data for all remaining participants ('additional subjects' and those who had not been seen by a MCHW) in the four geographic areas were also analysed to show how well these 'controls' reflected the wider cohort who did not receive the intervention or additional weight measures. Acceptability of the tools (including PDA) to MCHW and participants was assessed through discussions with the MCHW. Comparisons between the Vanguard cohort and controls were made using the $\chi^{2}$ test for categorical variables and $t$ test for continuous variables. Changes over time were compared using the paired $t$ test and changes between groups compared by analysis of variance. All tests were two-tailed with $P=0.05$ taken as significant. As this was a pilot study for a fully powered trial, incident diabetes was not systematically identified during this time period, awaiting a second round of screening at the trial midpoint.

\section{Results}

Table 2 shows the baseline characteristics of the Vanguard Study cohort, the fifty-two 'controls' and 1143 other participants from the four geographical areas. Those in the Vanguard Study included more participants with IGT/IFG than others in the area and were heavier.

The first PDA-recorded visit took place 351 (SD 110) (range 95-623) days after screening in the Vanguard Study cohort and 422 (SD 223) (range 161-665) days in the 'control' group. The intervention occurred (as per PDA) over 189 (SD 128) (range 6-485) days during the Vanguard Study period. Between one and seventeen (mean 3 (SD 2)) contacts were recorded with each participant during this time, although this would have excluded the initial visit(s) and incidental meetings (e.g. in the supermarket). MCHW reports indicated that the messages, toolkit and delivery approach were acceptable to both MCHW and participants. The PDA were shown to be easy to use among MCHW, and allowed them to record weight reliably; a small number of areas for upgrade of the software program were identified. No changes to the other toolkit components were required. One participant was excluded due to PDA data entry error.

Those with IGT/IFG, but not other participants, lost weight by the time of the first weighing. Significant weight loss also occurred between the first and last 


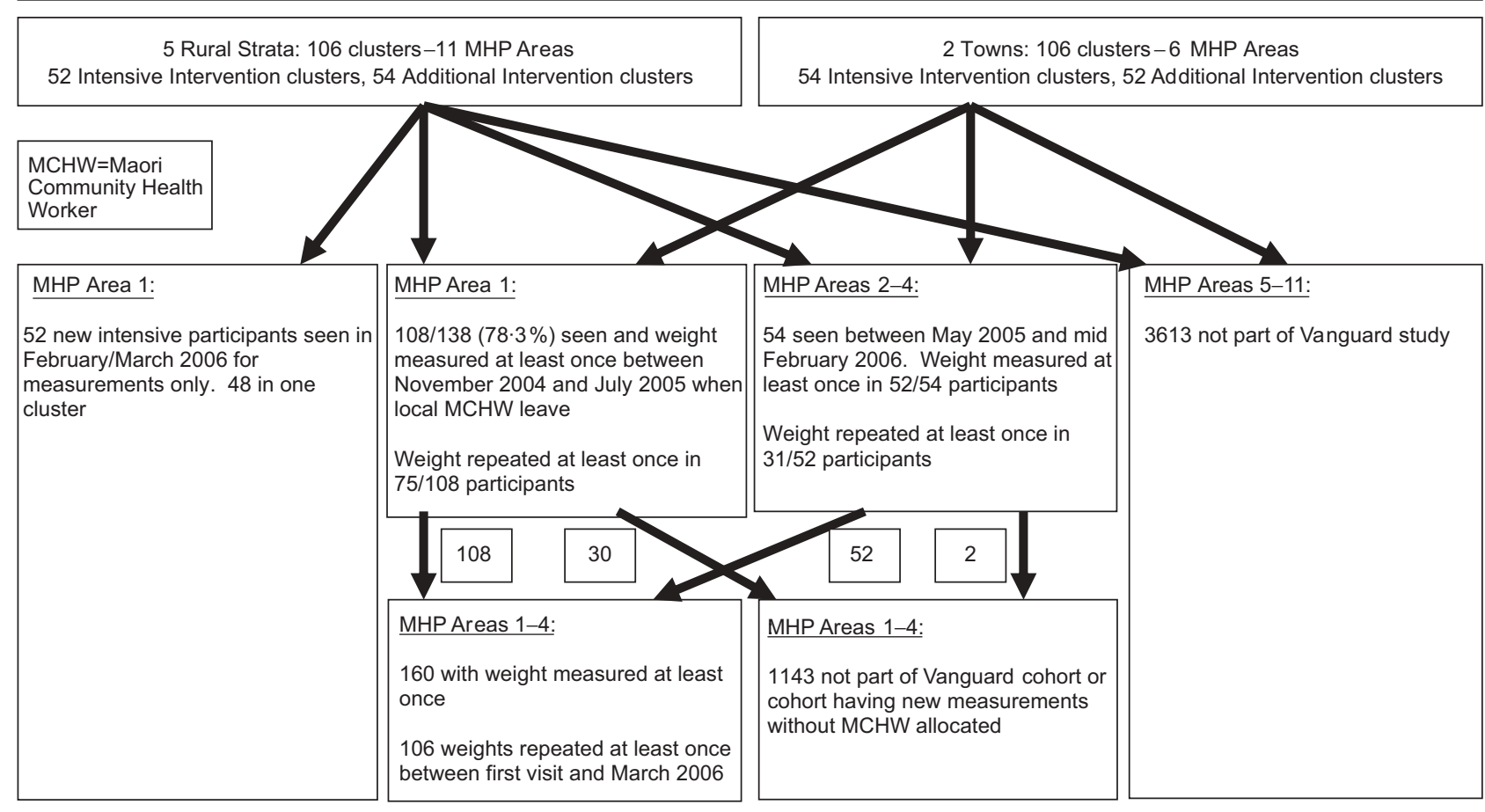

Fig. 1 Source of sample in the Vanguard Study

MCHW visits, independent of area (and therefore MCHW), gender (although significantly only among women) and initial glucose tolerance (although significantly only among those without known IGT/IFG). This translated into an overall weight loss from screening to last visit of $5 \cdot 2$ (SD 6.6) $\mathrm{kg}(P<0 \cdot 01)$ among those with IGT/IFG.

\section{Discussion}

The major additional strategy in Te Wai o Rona: Diabetes Prevention Strategy beyond our past approaches ${ }^{(8,11-13)}$ was the addition of the MCHW trainer, expected to be of most use in the first year and to be supplemented by group sessions, improvements in access to healthy food and physical activity options, and shifts in community attitude. The MCHW intervention was seen as the key to the downstream intervention activities. The Vanguard Study strongly suggests that our intervention was associated with weight loss, the major component in diabetes prevention $^{(5)}$. Although only a small fraction of the whole Te Wai o Rona: Diabetes Prevention Strategy cohort, this Vanguard Study is the largest intervention among Maori so far reported ${ }^{(32)}$, and confirms that weight management can be successfully achieved if undertaken in the appropriate manner.

The extent of the weight loss, particularly among those with IGT/IFG, was unexpected and at the same level as in the DPP ${ }^{(4)}$, although the bulk occurred in the period between screening and the first recorded encounter with the MCHW. During this time, participants were advised of their risk in the letter, advised to see their GP if any clinical reason arose (e.g. IGT/IFG) or for prior assessment for physical activity, and these could have contributed to this weight loss. Furthermore, the recruitment, and indeed the whole study process, was actively promoted in the media and at cultural events and was a major talking point in the community, and this also could have stimulated some individuals to adopt lifestyle change. However, intensively treated participants would have had one or more unrecorded MCHW encounters and these may have had a significant effect. These visits were not recorded as it was felt that the PDA could be intrusive at such a session, where the family and community ties, study and intervention process and overall trust building were more of a focus than the messages. Having said this, many participants were keen to commence and advice would have been given. In two of the Vanguard Study areas, the MCHW established walking groups, which although ultimately intended to be run by local leaders, would have been another unrecorded intervention activity.

Interpretation of the Vanguard Study findings is complex. The reproducibility by geographical, demographic and glucose tolerance group all suggest that among these individuals, the intervention was associated with weight loss. On the other hand, this was a small non-randomised 
Table 2 Te Wai o Rona: Diabetes Prevention Strategy - Vanguard Study cohort and controls, baseline data

\begin{tabular}{|c|c|c|c|c|c|c|c|c|}
\hline & \multicolumn{2}{|c|}{ Vanguard } & \multicolumn{2}{|c|}{ Controls } & \multirow[b]{2}{*}{$P$} & \multicolumn{2}{|c|}{ Others in area } & \multirow[b]{2}{*}{$P$ v. Vanguard } \\
\hline & Mean & SD & Mean & SD & & Mean & SD & \\
\hline & \multicolumn{2}{|c|}{$n 160$} & \multicolumn{2}{|c|}{$n 52$} & & \multicolumn{2}{|c|}{$n 1143$} & \\
\hline Age (years) & 47 & 13 & 50 & 13 & $0 \cdot 176$ & 46 & 13 & $0 \cdot 348$ \\
\hline IGT/IFG & \multicolumn{2}{|c|}{$27(16.9 \%)$} & \multicolumn{2}{|c|}{$11(21 \cdot 2 \%)$} & 0.553 & \multicolumn{2}{|c|}{$108(9 \cdot 4 \%)$} & 0.008 \\
\hline$\%$ Male & \multicolumn{2}{|c|}{$34 \cdot 4$} & \multicolumn{2}{|c|}{$40 \cdot 4$} & 0.506 & \multicolumn{2}{|c|}{$34 \cdot 5$} & $1 \cdot 00$ \\
\hline Fasting glucose (mM) & $5 \cdot 2$ & 0.6 & $5 \cdot 3$ & 0.5 & 0.641 & $5 \cdot 1$ & 0.6 & 0.061 \\
\hline $2 \mathrm{~h}$ glucose $(\mathrm{mM})$ & $5 \cdot 7$ & $1 \cdot 8$ & $6 \cdot 2$ & $2 \cdot 0$ & $0 \cdot 137$ & $5 \cdot 4$ & $1 \cdot 7$ & $0 \cdot 113$ \\
\hline $\mathrm{HbA1c}(\%)$ & $5 \cdot 9$ & 0.4 & $5 \cdot \overline{9}$ & $0 \cdot 4$ & 0.507 & $5 \cdot 8$ & 0.4 & 0.236 \\
\hline Weight (kg) & $93 \cdot 5$ & $24 \cdot 2$ & $90 \cdot 4$ & $18 \cdot 1$ & $0 \cdot 340$ & $89 \cdot 5$ & $22 \cdot 5$ & 0.051 \\
\hline $\operatorname{BMI}\left(\mathrm{kg} / \mathrm{m}^{2}\right)$ & $34 \cdot 1$ & 8.5 & $32 \cdot 7$ & $6 \cdot 5$ & $0 \cdot 221$ & $32 \cdot 3$ & $7 \cdot 5$ & 0.014 \\
\hline Weight change $(\mathrm{kg})$ from screening to & \multicolumn{2}{|c|}{$n 160$} & \multicolumn{2}{|c|}{$n 52$} & & & & \\
\hline No diagnosed IGT/IFG & $-0 \cdot 3$ & $5 \cdot 3$ & +0.6 & $8 \cdot 5$ & 0.464 & & & \\
\hline IGT/IFG & $-3 \cdot 7^{\star \star}$ & $5 \cdot 6$ & -1.9 & $3 \cdot 4$ & 0.317 & & & \\
\hline Weight change from first to last visit $(\mathrm{kg})$ & \multicolumn{2}{|c|}{$n 106$} & & & & & & \\
\hline Overall & $-1 \cdot 3^{\star \star \star}$ & $3 \cdot 6$ & & & & & & \\
\hline Area 1 & $-0 \cdot 9^{*}$ & $3 \cdot 7$ & & & & & & \\
\hline Areas $2-4$ & $-2 \cdot 2^{* \star *}$ & $3 \cdot 1$ & & & & & & \\
\hline No known IGT/IFG & $-1 \cdot 2^{\star \star \star}$ & $3 \cdot 4$ & & & & & & \\
\hline IGT/IFG & $-1 \cdot 4$ & $4 \cdot 3$ & & & & & & \\
\hline Men & $-1 \cdot 1$ & $4 \cdot 0$ & & & & & & \\
\hline Women & $-1 \cdot 4^{\star \star \star}$ & $3 \cdot 3$ & & & & & & \\
\hline \multicolumn{3}{|c|}{ Weight change from screening to last visit $(\mathrm{kg})$} & & & & & & \\
\hline Normal & $-0 \cdot 3$ & $10 \cdot 0$ & & & & & & \\
\hline IGT/IFG & $-5 \cdot 2^{\star \star}$ & $6 \cdot 6$ & & & & & & \\
\hline
\end{tabular}

IGT, impaired glucose tolerance; IFG, impaired fasting glucose; $\mathrm{HbA} 1 \mathrm{C}$, glycosylated $\mathrm{Hb}$.

${ }^{\star} P<0.05,{ }^{* \star} P<0.01,{ }^{\star \star \star} P<0.001$ (paired $t$ test within group or $\chi^{2}$ test).

group with the potentially more interested participants involved: this may not reflect what would happen over the wider population or over a longer period of time (although on average the intervention had been in place for at least 6 months). We were particularly encouraged by the impact across different MCHW, suggesting that the intervention effect was likely to be greater than the MCHW personalities. Ultimately, over twenty MCHW have been trained. Unfortunately, the Te Wai o Rona: Diabetes Prevention Strategy could not be completed within the first 3 years and no new funding was made available for the research to continue.

At the heart of the intervention was the 'message' approach, designed to create small successes and thereby promote recognition of the ability to succeed in changing lifestyle ${ }^{(26)}$. The intervention also included identification and the development of strategies to deal with obstacles to lifestyle change, while promoting positive aspects of healthy choices ${ }^{(27)}$. In the intervention development stage, preferred forms of physical activity (e.g. walking) were identified and the toolkit was built around these preferences. One area of conflict between contemporary lifestyle advice and Maori preferences was over the protein, fat and carbohydrate content of the diet. The precolonial diet ${ }^{(29)}$ varied according to area (e.g. those living by the sea ate more seafood, those by rivers, eel and so forth), but contemporary preferences relate more to a higher fat and protein content than recommended ${ }^{(33)}$.
Furthermore, there is good evidence that low carbohydrate diets are associated with significant weight loss (albeit with adverse metabolic consequences) ${ }^{(34)}$. In view of this, a higher proportion of protein (with low saturated fat content) was actively promoted in the messages, although the differences with the Atkins diet were also emphasised. Further analysis is currently underway on the lifestyle choices at baseline.

In conclusion, we have recruited a large cohort of Maori and their family members into a randomised cluster-controlled trial of the impact of personal lifestyle change supported by changes in the surrounding social and physical environment. The study is powered to show a $35 \%$ reduction in incident diabetes and improvements in diabetes risk factors. The Vanguard Study confirmed the effectiveness of the approach, allowed modification to the tools and suggested that the study goals would have been likely to be achieved.

\section{Acknowledgements}

Source of funding: Funding was provided by Health Research Council, Waikato District Health Board, Lakes District Health Board, Ministry of Health, Sport and Recreation New Zealand, Southern Trust, Waikato Local Diabetes Team and Merck Sharp and Dohme. Support in kind was provided by Roche Diagnostics, Pathlab, 
Medlab, University of Auckland, Auckland University of Technology, Wintec, Te Hotu Manawa Maori, Eggs Inc., Vodafone, Rivermill Bakers, Sun Fruit.

Conflict of interest: There was no conflict of interest. Author contributions: All authors substantially contributed to the design of the experiment, collection of data, analysis of data, writing of the manuscript and provision of significant advice and consultation in its preparation. The project was led by Professor David Simmons with Elaine Rush in the Waikato and Dr Nic Crook in the Lakes District.

Acknowledgements: We thank the investigator group, Kaitiaki, Maori community health workers, Te Wai o Rona: Diabetes Prevention Strategy Project team and local health service staff for their varied contributions to the study.

\section{References}

1. Tuomilehto J, Lindstrom J, Eriksson JG et al. (2001) Prevention of type 2 diabetes mellitus by changes in lifestyle among subjects with impaired glucose tolerance. N Engl J Med 344, 1343-1350.

2. Pan XR, Li GW, Hu YH et al. (1997) Effects of diet and exercise in preventing NIDDM in people with impaired glucose tolerance. The Da Qing IGT and Diabetes Study. Diabetes Care 20, 537-544.

3. Ramachandran A, Snehalatha C, Mary S, Mukesh B, Bhaskar AD \& Vijay V (2006) The Indian Diabetes Prevention Programme shows that lifestyle modification and metformin prevent type 2 diabetes in Asian Indian subjects with impaired glucose tolerance (IDPP-1). Diabetologia 49, 289-297.

4. Knowler WC, Barrett-Connor E, Fowler SE et al. (2002) Reduction in the incidence of type 2 diabetes with lifestyle intervention or metformin. $N$ Engl J Med 346, 393-403.

5. Ratner R, Goldberg R, Haffner S et al. (2005) Impact of intensive lifestyle and metformin therapy on cardiovascular disease risk factors in the diabetes prevention program. Diabetes Care 28, 888-894.

6. Lindstrom J, Ilanne-Parikka P, Peltonen M et al. (2006) Sustained reduction in the incidence of type 2 diabetes by lifestyle intervention: follow-up of the Finnish Diabetes Prevention Study. Lancet 368, 1673-1679.

7. Herman WH, Brandle M, Zhang P et al. (2003) Costs associated with the primary prevention of type 2 diabetes mellitus in the diabetes prevention program. Diabetes Care 26, 36-47.

8. Simmons D, Voyle J, Swinburn B \& O'Dea K (1997) Community-based approaches for the primary prevention of non-insulin-dependent diabetes mellitus. Diabet Med 14, 519-526.

9. Daniel M, Green LW, Marion SA et al. (1999) Effectiveness of community-directed diabetes prevention and control in a rural Aboriginal population in British Columbia, Canada. Soc Sci Med 48, 815-832.

10. Rowley KG, Daniel M, Skinner K, Skinner M, White GA \& O'Dea K (2000) Effectiveness of a community-directed 'healthy lifestyle' program in a remote Australian aboriginal community. Aust $N Z J$ Public Health 24, 136-144.

11. Simmons D, Fleming C, Voyle J, Fou F, Feo S \& Gatland B (1998) A pilot urban church-based programme to reduce risk factors for diabetes among Western Samoans in New Zealand. Diabet Med 15, 136-142.

12. Voyle JA \& Simmons D (1999) Community development through partnership: promoting health in an urban indigenous community in New Zealand. Soc Sci Med $\mathbf{4 9}$, 1035-1050.

13. Simmons D, Voyle JA, Fou F, Feo S \& Leakehe L (2004) Tale of two churches: differential impact of a church-based diabetes control programme among Pacific Islands people in New Zealand. Diabet Med 21, 122-128.

14. O'Dea K (1984) Marked improvement in carbohydrate and lipid metabolism in diabetic Australian aborigines after temporary reversion to traditional lifestyle. Diabetes $\mathbf{3 3}$, 596-603.

15. Joshy G \& Simmons D (2006) Epidemiology of diabetes in New Zealand: revisit to a changing landscape. $N Z$ Med J 119, U1999.

16. Burke JP, Williams K, Narayan KM, Leibson C, Haffner SM \& Stern MP (2003) A population perspective on diabetes prevention: whom should we target for preventing weight gain? Diabetes Care 26, 1999-2004.

17. Israel BA, Schulz AJ, Parker EA, Becker AB, Allen AJ \& Guzman JA (2003) Critical issues in developing and following community-based participatory research principles. In Community-Based Participatory Research for Health, pp. 53-76 [M Minkler and N Wallerstein, editors]. San Francisco, CA: Jossey-Bass.

18. Alberti KG \& Zimmet PZ (1998) Definition, diagnosis and classification of diabetes mellitus and its complications. Part 1: diagnosis and classification of diabetes mellitus provisional report of a WHO consultation. Diabet Med 15, 539-553.

19. Soderberg S, Zimmet P, Tuomilehto J et al. (2004) High incidence of type 2 diabetes and increasing conversion rates from impaired fasting glucose and impaired glucose tolerance to diabetes in Mauritius. J Intern Med 256, 37-47.

20. Simmons D, Thompson CF \& Volklander D (2001) Polynesians: prone to obesity and type 2 diabetes mellitus but not hyperinsulinaemia. Diabet Med 18, 193-198.

21. Statistics New Zealand (2004) Population Projections. Wellington: Statistics New Zealand.

22. Simmons D \& Mesui J (1999) Decisional balance and stage of change in relation to weight loss, exercise and dietary fat reduction among Pacific Islands people. Asia Pac J Clin Nutr 8, 39-45.

23. Cardinal BJ, Esters J \& Cardinal MK (1996) Evaluation of the revised physical activity readiness questionnaire in older adults. Med Sci Sports Exerc 28, 468-472.

24. Simmons D, Thompson CF \& Engelgau MM (2005) Controlling the diabetes epidemic: how should we screen for undiagnosed diabetes and dysglycaemia? Diabet Med 22, 207-212.

25. Tregonning PB, Simmons D \& Fleming C (2001) A community diabetes educator course for the unemployed in South Auckland, New Zealand. Diabetes Educ 27, 94-100.

26. Bandura A (1982) Self-efficacy mechanism in human agency. Am Psychol 37, 122-147.

27. Prochaska JO (1994) Strong and weak principles for progressing from precontemplation to action on the basis of twelve problem behaviors. Health Psychol 13, $47-51$.

28. Elley CR, Kerse N, Arroll B \& Robinson E (2003) Effectiveness of counselling patients on physical activity in general practice: cluster randomised controlled trial. Bmj 326, 793.

29. Cambie RC \& Ferguson LR (2003) Potential functional foods in the traditional Maori diet. Mutat Res 523-524, 109-117. 
30. Ministry of Health (2003) A Portrait of Health: Key Results of the 2002/2003 New Zealand Health Survey. Wellington: Ministry of Health.

31. West DS, DiLillo V, Bursac Z, Gore SA \& Greene PG (2007) Motivational interviewing improves weight loss in women with type 2 diabetes. Diabetes Care 30, 1081-1087.

32. Murphy E, McAuley KA, Bell D et al. (2003) A new approach to design and implement a lifestyle intervention programme to prevent type 2 diabetes in New Zealand Maori. Asia Pac J Clin Nutr 12, 419-422.

33. Ministry of Health (2003) Healthy Eating-healthy Action Oranga Kai - Oranga Pumau: a Strategic Framework. Wellington: Ministry of Health.

34. Foster GD, Wyatt HR, Hill JO et al. (2003) A randomized trial of a low-carbohydrate diet for obesity. $N$ Engl J Med 348, 2082-2090. 